\title{
Kritik der Biopolitik
}

\section{Überlegungen zur biopolitischen Gouvernementalität in Zeiten des Coronavirus und die Möglichkeit ihrer Kritik}

\section{A Critique of Biopolitics \\ Thoughts on biopolitical governmentality during Covid-19 and the potential for its critique}

\section{Sebastian Krach, Wien}

Zusammenfassung: Aktuelle Debatten zu gesellschaftspolitischen Folgen der Corona-Pandemie zeigen, dass Intellektuelle wie Giorgio Agamben und Roberto Esposito den Begriff „Biopolitik“ ins Treffen führen, um Regierungsmaßnahmen zur Eindämmung des Virus zu analysieren. Seit Michel Foucaults Überlegungen zur Funktionsweise und Genealogie der Biopolitik birgt der Begriff jedoch eine gewisse Problematik: Aufgrund strukturell bedingter Mechanismen der Inklusion und Exklusion menschlichen Lebens gelingt es den biopolitischen Modellen nach Agamben und Esposito nicht - so die These -, ein zentrales Element des Politischen zu beschreiben. Unberücksichtigt bleibt die Möglichkeit des Widerstands und der Kritik an Regierungsmaßnahmen; eine Möglichkeit, die gerade die Heterogenität politischer Ordnungsstrukturen anzeigt. Im Zuge der Analytik moderner Machttechniken verschiebt Foucault anders als Agamben und Esposito den Fokus von der Biopolitik hin zu einem umfassenderen Paradigma des „Regierens“, der Gouvernementalität. Infolgedessen lässt sich die Biopolitik als Regierungsweise thematisieren, mit der immer schon Formen widerständigen Handelns einhergehen. Um dieser Perspektive Rechnung zu tragen, argumentiert mein Beitrag mit Foucault gegen die primär strukturale Auffassung (bio)politischer Ordnungen nach Agamben und Esposito.

Schlüsselwörter: Biopolitik, Widerstand, Foucault, Agamben, Esposito

Abstract: Current debates on the socio-political consequences of the coronavirus pandemic show that intellectuals such as Giorgio Agamben or Roberto Esposito use 
the term "biopolitics" to analyse government measures to contain the virus. However, since Michel Foucault's considerations on the functioning and genealogy of biopolitics, the concept has presented a specific problem: the hypothesis states that due to the structurally determined mechanisms of inclusion and exclusion that are inherent to concepts of biopolitics, these concepts are unable to fully grasp the ideas of criticism, resistance and the fracturing of political orders. Unlike Agamben and Esposito, Foucault shifts his focus gradually from analysing biopolitics to thinking about the general paradigm of "governing" people - what he calls "governmentality". In this way, he invokes the possibility of addressing biopolitics as techniques to govern people that are potentially always subject to criticism and forms of political resistance. To take that perspective into account, my contribution argues against the mere structuralist view of Biopolitics according to Agamben and Esposito.

Keywords: Biopolitics, Resistance, Foucault, Agamben, Esposito

\section{Einleitung: Coronavirus und die Biopolitik}

In Anbetracht des anhaltenden sozialen Ausnahmezustandes, den die Corona-Pandemie weltweit beschert, ist es nicht verwunderlich, dass zahlreiche Analysen den Begriff der „Biopolitik“ bemühen, um die derzeitigen Maßnahmen zur Eindämmung des Virus theoretisch einzuordnen. Denn rezent werden biopolitische Maßnahmen zumeist als ein Versuch gewertet, Gefahren für das Leben einer Bevölkerung zu reduzieren, womit aktuell auch die Beschränkung von individuellen Freiheitsrechten in Kauf genommen wird. Giorgio Agamben und Roberto Esposito, zwei wichtige Persönlichkeiten der italienischen Gegenwartsphilosophie, kommentieren im Frühjahr 2020 ebenfalls gesellschaftspolitische Entwicklungen inmitten der Anfangszeit der Pandemie. Beide Denker eint die Einschätzung, dass sich das Konzept der „Biopolitik“ eignet, um auf die innere Logik behördlichen Vorgehens zur Eindämmung des Virus zu verweisen. Zu nennen sind Regierungsmaßnahmen wie das „Social Distancing“, das Tragen von Mund-Nasen-Schutzmasken, die verordnete Heimquarantäne und Ausgangssperren, die Schließung nationaler Grenzen sowie die generelle Erschwerung des transnationalen Personenverkehrs.

In Situationen, in welchen ein Virus den menschlichen Körper befällt, lassen sich biopolitische Maßnahmen laut Esposito als Versuch begreifen, das biologische Leben nicht bloß des Einzelnen, sondern eines ganzen Bevölkerungskörpers zu sichern. Hierbei besteht nach Esposito jedoch die Gefahr, das institutionalisierte Leben in seinen soziokulturellen Ausformungen 
dauerhaft auf einen rein biologischen Status zu reduzieren. Diesen speziellen Umstand bezeichnet Esposito in Anlehnung an Walter Benjamin als eine Reduktion auf „nacktes“ oder „bloßes“ Leben (Esposito 2020). Gleichsam äußert sich hierin wiederum die steigende Bedeutung der Notstandsgesetzgebung, die subjektive Freiheitsrechte unter dem Kalkül des Bevölkerungsschutzes beschneidet. Insbesondere Agamben moniert zu Beginn der Pandemie jene Beschneidung der Freiheitsrechte infolge der aktiven Herbeiführung von gesellschaftlichen und rechtlichen Ausnahmezuständen. Er meint: „First and foremost, what is once again manifest here is the growing tendency to use the state of exception as a normal governing paradigm" (vgl. Agamben 2020). Dabei drückt der Ausnahmezustand für Agamben und Esposito nicht einzig die Reduktion der Vielfalt institutionalisierter Lebensformen auf die Biologie des Lebens aus. Zugleich bedeutet die Ausnahme auch einen Ausschluss aus politisch-juridischen Ordnungen. Beachtenswert ist dies insofern, als die politisch-juridischen Ordnungen der meisten europäischen Staaten bestimmte Freiheitsrechte genuin zu bewahren suchen.

Sowohl Agamben als auch Esposito assoziieren „Biopolitik“ mit der grundsätzlichen Konstitution juridisch-politischer Ordnungen über Modi des Ein- und Ausschlusses menschlichen Lebens. Zuvorderst bilden hierbei Michel Foucaults Erörterungen zum Begriff der Biopolitik ${ }^{1}$ die gemeinsame Referenz. Dennoch ist einleitend anzumerken, dass sich nicht nur in Absetzung von Foucault, sondern auch in dessen unmittelbarer Nachfolge verschiedenartige Rezeptionswege und Forschungsinteressen gen Ende des letzten Jahrhunderts herausbilden, die mit dem Begriff der Biopolitik operieren. Das Spektrum des Begriffgebrauchs reicht von der Humangenetik und Biotechnologie hin zur Reproduktionsmedizin und Stammzellenforschung. ${ }^{2}$

$1 \quad$ Der Begriff der Biopolitik ist jedoch nicht von Foucault selbst eingeführt worden, sondern besitzt einige Vorläufer, wie sowohl Thomas Lemke (2008) als auch Esposito (2008a, 13ff.) jeweils erörtern.

Vgl. hierzu die Sammelbände: Buchstein und Beier (2011), Geyer (2001), van den Daele (2005), Spieker (2009) sowie mit einem feministischen Schwerpunkt Graumann und Schneider (2003). Zu einem konsequent weitergeführten und für die Gegenwart neu ausgelegten Konzept der Biopolitik im Ausgang von Foucault vgl. Rose (2014), der den Fokus weg vom Bevölkerungsdiskurs hin auf das scheinbar rezent biopolitisch agierende Individuum richtet. $\mathrm{Zu}$ nennen sind zuletzt auch die Textsammlung Braun und Gerhards (2019) zum Versuch einer sozialtheoretischen Neubestimmung der Biopolitik im Anschluss an Foucault sowie der Sammelband Muhle und Thiele (2011), der sich 
In letztgenannten Forschungsrichtungen versteht man unter Biopolitik also primär die politische Auseinandersetzung mit konkreten medizinethischen Fragestellungen, die sodann mit der Organisation des Gesundheitswesens zusammenlaufen. Die Überlegungen Foucaults, Agambens und Espositos zielen dagegen auf eine allgemeinere Ebene der Regierungspraxis sowie der Analyse von Ausschlüssen aus den politisch-rechtlichen Ordnungsgefügen. ${ }^{3}$ In Folge der vielseitigen Begriffsanwendung könnte letztlich der Eindruck einer inflationären, gar diffusen Verwendung des Begriffs der „Biopolitik“ entstehen (vgl. Pieper et al. 2011, 7; vgl. Braun und Gerhards 2019, 4).

Der vorliegende Forschungsbeitrag widmet sich einem grundlegenden Problem in den Konzeptionen der Biopolitik nach Agamben und Esposito. ${ }^{4}$ Insofern genannte Denker biopolitische Überlegungen ausschließlich auf das Strukturhafte der einschließenden und ausschließenden Mechanismen politischer Ordnungen richten, versäumen sie es meines Erachtens, ein politisches Moment der Kritik und des Widerstandes auszuloten. In dieser Hinsicht rezipieren Agamben und Esposito die Schriften und Aufzeichnungen Foucaults bloß selektiv, denn Foucault führt seit 1978 den Begriff der Biopolitik mit dem Verständnis von „Gouvernementalität“ eng. Dieser Umstand findet bei Agamben und Esposito keine Berücksichtigung. Doch gerade die Inblicknahme des Regierens von Menschen zeigt, dass Biopolitik immer schon mit potenzieller Widerständigkeit und Kritik konfrontiert ist. Dies kann theoretisch insofern konzeptualisiert werden, als die Praxis des Regierens in Foucaults Schriften seit 1978 zum Paradigma der Machtanalyse avanciert. Da Foucault bereits 1976 formuliert, dass Macht nicht ohne Widerstand zu denken ist, schließt sich der Kreis zurück zur Biopolitik und zum Verständnis der Gouvernementalität. Die aktuellen Widerstände gegen Maßnahmen zur Bekämpfung der Pandemie sind vielfältiger Natur und

insbesondere den Verbindungslinien zwischen Foucault'scher Machtanalytik und der Biopolitik widmet.

3 Wie jedoch mit Matthias Bohlender argumentiert werden kann, sind die Grenzen zwischen bioethischen und biopolitischen Debatten fließend, denn auch in bioethischen Debatten stellt man sich die Fragen nach den „Akzeptabilitätsbedingungen“ lebenswerten Lebens (vgl. Bohlender 2006, 99) - ein Topos, der in den Schriften Foucaults, Agambens und Espositos wieder aufscheint.

4 Damit wird ein weiterer Rezeptionsweg des Foucault'schen Verständnisses von Biopolitik nach Hardt und Negri (2002) vernachlässigt. Hierzu vgl. zum Beispiel den Sammelband von Pieper et al. (2007). 
reichen von fundierter Kritik bis zu zahlreichen inkonsistenten Verschwörungstheorien, die es voneinander zu unterscheiden gilt. Eine Theorie der Biopolitik, welche für sich beansprucht, ein Verständnis für die Konstitution politischer Ordnungen zu liefern, sollte meines Erachtens in der Lage sein, Widerständigkeit konzeptuell zu erfassen. Aus diesem Grund zielt der Beitrag auf eine Ergänzung der Ansichten Agambens und Espositos, die es unterlassen, politische Widerständigkeit zu thematisieren.

Um den konzeptionellen Umgang mit dem Begriff der Biopolitik in den Ausführungen Agambens und Espositos zu kritisieren, werde ich in zwei Schritten verfahren. Zunächst soll (1.) ausführlich dargelegt werden, weshalb die Rede von der Biopolitik zumeist der Betrachtung inhärenter Inklusionsund Exklusionsmechanismen verhaftet bleibt und es nicht gelingt, widerständige Praxis in die Theoretisierung der Biopolitik zu integrieren. Hierzu werde ich zunächst die biopolitischen Positionen Foucaults, Agambens und Espositos skizzieren sowie diesbezügliche Problemhorizonte diskutieren. Darauf folgt (2.) die Absicht, wiederum mit Foucault zu verdeutlichen, dass Biopolitik als Regierungsweise sehr wohl einem Moment des Widerständigen exponiert ist und sich politische Ordnungen daher ungeachtet möglicher struktureller Eigenschaften stets als heterogen erweisen. Zur Bewerkstelligung dieses Vorhabens folgt meine Argumentation Foucaults Ausführungen zurück zur berühmten Neuausrichtung seiner Machtanalytik in Der Wille zum Wissen aus dem Jahre 1976. Zuletzt werde ich im Rahmen der Konklusion (3.) die gewonnenen Einsichten am Beispiel jenes Ausnahmezustandes erproben, den das Coronavirus gegenwärtig mit sich bringt.

\section{Biopolitische Inklusions- und Exklusionsmechanismen}

Foucault begreift die Biopolitik in Der Wille zum Wissen (1976) sowie dem Vorlesungsband In Verteidigung der Gesellschaft (1996) als eine seit dem 18. Jahrhundert in Europa erstarkende Form der Regierung von Menschen. Die Rede ist von einer „historische[n] Zäsur“ (Lemke 2008, 80), die auf den Rationalisierungsversuch sozioökonomischer Probleme der Bevölkerung5

$5 \quad$ Wie Foucault in der Vorlesung vom 18. Jänner 1978 nachzeichnet, besteht im 18. Jahrhundert das Problem der Bevölkerung in Form von Nahrungsmängeln. Dieser Zustand der Knappheit führt schließlich zur physiokratischen Kritik an preislichen Regulierungsmechanismen der merkantilistisch ausgerichteten Staatsräson und mündet in einen marktwirtschaftlichen Liberalismus des „Laissez-faire“. Für eine kompakte Rekonstruktion dieser his- 
folgt (vgl. Foucault 1976, 136; vgl. Foucault 2006, 435). Erstmals wird die Ganzheit eines Bevölkerungskörpers (vgl. Foucault 1996, 289f.) nicht einzig als Summe von Rechtssubjekten (vgl. Foucault 2004, 108, 524), sondern als eigene wissensfähige Größe konstituiert, statistisch vermessen, an regulatorischen Normen ausgerichtet und nach Maßstab dieser Normen strategisch verwaltet (vgl. Foucault 1996, 298f.). ${ }^{6}$

Das Einwirken auf globale Bevölkerungsphänomene wie die öffentliche Gesundheit und Hygiene, die Geburten- und Sterblichkeitsrate, die Lebensdauer der Menschen wie auch Migrationsbewegungen gelingt maßgeblich über die biologische Kategorie des „Lebens“ (vgl. Foucault 1976, 135; vgl. Foucault 1996, 290).7 Aus der modernen Biologie stammt das Wissen über eine wesensmäßige Natürlichkeit des Lebens, das nach Foucault auf kollektiver Ebene als serieller, demographisch konstanter „Gesamtprozess“ in Erscheinung tritt (Foucault 1996, 294). Biopolitik versteht sich in diesem Sinne als die Summe an Maßnahmen zur Kontrolle von Risiken und wahr-

torischen Entwicklung ökonomischen Denkens anhand der Ausführungen Foucaults siehe Bohlender 2006.

6 Foucault differenziert zwischen Normation und Normierung (vgl. 2004, 98f.). Die Norm, welche in der Biopolitik zum Einsatz kommt, richtet sich an der Vorgabe des biologischen Lebens aus, insofern die regelmäßigen Prozesse des Lebens als Maßstab für die Einwirkung auf die Bevölkerung herhalten. Dies nennt Foucault „Normation“, im Gegensatz zur „Normierung“, die über die Disziplinen erfolgt. Die statistische Normalverteilung, die Normalisierung von Phänomenen des Lebens wie auch die Normalisierungsgesellschaft (vgl. Foucault 1976, 139; vgl. Foucault 1996, 299) - all diese Begriffe korrespondieren in zentraler Hinsicht mit Foucaults Verständnis von Biopolitik. Um die Ausrichtung an der Norm des Lebens zu bewahren, werden Sicherheitsmechanismen installiert (vgl. Foucault 1996, 290), die in den Bereich des Sicherheitsdispositivs fallen (vgl. Foucault 2004, 39f.).

7 Auf die Unterbestimmtheit des Lebensbegriffs in den Arbeiten Foucaults verweist Maria Muhle (2008, 10f.), die ein Buch zur Genealogie des Lebensbegriffs im Werk Foucaults vorgelegt hat. Mit dem neu konstituierten Wissenskomplex der Biologie des Lebens (vgl. Unterthurner 2016, 167) wird seit dem 18. Jahrhundert ein Prozess der autonomen Selbstorganisation des Lebens unterstrichen (vgl. Lemke 2004, 958). Muhles These, nach der die Biopolitik im Sinne einer formalen Analogie dem biologischen Lebensprozess selbst gleicht (vgl. Muhle 2008, 261), geht meines Erachtens einen Schritt zu weit. Es handelt sich nicht etwa um eine strategische Imitation, sondern vielmehr richten sich Regierungsweisen an dem biologischen Wissen über die Konstanten des Lebens aus und üben dahingehend Macht aus. 
scheinlichen Entwicklungen, die das „Naturphänomen“ Bevölkerung betreffen (Foucault 2004, 110; vgl. Foucault 2004, 92ff.; vgl. Foucault 1996, 294).

Ferner eignet der Biopolitik eine lebenssteigernde und -vervielfältigende, schützende sowie gesundheitsfördernde Funktion. Thomas Bedorf präzisiert in dieser Hinsicht gelungen: „Das Leben (bíos) und die Lebensfähigkeit der Population steigern zu wollen, hat zur Folge, dass das Leben keine Gnade mehr ist, die das Recht gewährt [...], sondern eine Aufgabe, die zu erfüllen ist“ (Bedorf 2013, 78). Mit dieser „biologische[n] Modernitätsschwelle“ reflektiert sich laut Foucault erstmals „das Biologische im Politischen“ (Foucault 1976, 138). Zusammenfassend ermöglicht das Wissen um die „biologischen Prozesse der Menschengattung“ (Foucault 1996, 291) die Bevölkerung mithilfe von Sicherheitsdispositiven sowie der politischen Ökonomie zu durchdringen, zu formen und zu korrigieren (vgl. Foucault 2004, 111, 162, 523). Biopolitische Regierungspraktiken finden somit Einzug in Institutionen wie die Medizin, die Polizeiarbeit sowie die Planung und Organisation von Städten (vgl. Foucault 1996, 295f., 298). ${ }^{8}$

Hervorzuheben ist, dass sich die Biopolitik nach Foucault vom Modus der souveränen oder auch als juridisch bezeichneten Machtausübung eines Herrschers über seine Untertanen unterscheidet. Vermittels Gesetzen steht es dem Herrschenden in dieser Logik zu, die Untergebenen zur eigenen Verteidigung zu liquidieren oder aber leben zu lassen und auf ihre Körper und Arbeitskraft zuzugreifen (vgl. Foucault 1976, 132). Wie bereits ausgeführt, besteht die historische Transformation im sukzessiven Wechsel der Regierungsweise hin zu einer „politischen Macht“ über das Leben der Bevölkerung (Foucault 1976, 134), d.i. ebenjene Art und Weise, die „biologische Existenz einer Bevölkerung" zu schützen und zu steigern (vgl. Foucault 1976, 132f., 139). Dagegen wird die souveräne Machtausübung eines Herrschers, Königs oder anderer Figuren der Souveränität durch Verbote, Repressionen, Ausgrenzung und die Macht über Leben und Tod der Untertanen charakterisiert.

Die souveräne Macht über das Leben wird jedoch nicht gänzlich ausgesetzt oder einfach abgelöst. Prinzipiell gilt, dass sich Formen der Macht

8 Zentralen Stellenwert in der Analyse der Biopolitik respektive Bio-Macht besitzt auch das Sexualitätsdispositiv, welches scharnierartig zwischen der kollektiven Ebene der Bevölkerung und derjenigen des Individuums Effekte zeitigt (vgl. Foucault 1976, 140ff.; vgl. Foucault 1996, 297). Auf welche Weise der Sex nach Foucault mit dem Begriff des Lebens korrespondiert, ist eine Fragestellung, der in vorliegender Arbeit nicht weiter nachgegangen werden kann. 
überlagern, verzahnen und in verschiedenen zeitlichen und örtlichen Kontexten unterschiedliche Dominanz aufweisen (vgl. Foucault 1976, 144; vgl. Foucault 2004, 159f.). So tritt zur biopolitischen Steigerungsfunktion des Lebens ein moderner, evolutionsbiologischer Staatsrassismus hinzu (vgl. Foucault 1976, 144), der die Funktion der souveränen Macht erfüllt, den Bevölkerungskörper zu fragmentieren. Dies bedeutet, dass vor Fremden, Gefährlichen und Delinquenten Schutz geboten und die eigene „Rasse“ gestärkt wird, indem bestimmte Menschen ausselektiert, getötet, vertrieben oder einem erhöhten Todesrisiko ausgesetzt werden (vgl. Foucault 1996, 301ff.). Folgen wir Foucault, so zielt ein derartiger Staatsrassismus letztlich auf die Steigerung der Gesundheit, Reinheit und Homogenität des Bevölkerungskörpers, der Rasse oder Nation. Ein Umstand, der im NS-Regime einen traurigen Höhepunkt erfahren hat (vgl. Foucault 1996, 306ff.).

Die gleichlaufenden Funktionen der Lebenssteigerung und Ausgrenzung beziehungsweise gar Tötung bestimmten Lebens werden in der Rezeption des Öfteren als Paradoxie (vgl. Gorgoglione 2016) oder Antinomie der Biopolitik (vgl. Esposito 2014, 98) wahrgenommen. Sie sind nach Foucault jedem modernen Staatswesen inhärent (vgl. Foucault 1996, 308). Dennoch bleibt der Konnex zwischen Biopolitik und Rassismus sowie Foucaults generelles Verständnis des Rassismus berechtigterweise nicht vor Kritik verschont. ${ }^{9}$ Was bei aller Kritik am Rassismusbegriff Foucault'scher Prägung fortbesteht, sind jedoch die scheinbar inhärenten und souveränen Exklusionsmechanismen der Biopolitik. Die damit einhergehende Fragmentierung des Bevölkerungskörpers stellt einen zentralen Topos in den Schriften Espositos und Agambens dar. Sprechen beide aktuell von „Biopolitik“, so stellen sie im Anschluss an Foucault ein Modell politischer Ordnungen vor, das über ein Innen und Außen politischer Ordnungen intelligibel wird. Mit dem

9 Lemke und Sarasin kritisieren bspw. die Uneindeutigkeit, fehlende Trennschärfe sowie historische Mängel des Foucault'schen Rassismusbegriff (vgl. Sarasin 2003, 66ff.; vgl. Lemke 2003, 162f.). Demgegenüber hebt Sarasin mit Anleihen aus der Diskurstheorie Chantal Mouffes und Ernesto Laclaus ein rassistisches Imaginäres der Biopolitik hervor, welches für eine Bevölkerung identitätsstiftend wirke (vgl. Sarasin 2003, 76, 68ff.). Hingegen gebraucht Mike Laufenberg den Foucault'schen Rassismusbegriff auf affirmative Weise, um gezielt Hierarchisierungen und Minorisierungen innerhalb einer Gesellschaft hervorzuheben (vgl. Laufenberg 2016, 28). Vgl. hierzu auch Ulrich Bröckling, der dem biopolitischen Rassismus die Funktion zuschreibt, zwischen höherwertigem und minderwertigem Leben zu unterscheiden (Bröckling 2010, 413). 
im Folgenden zu erläuternden „Immunisierungsparadigma“ nach Esposito äußert sich die Fragmentierung der Bevölkerung und die Konstitution einer politischen Ordnung unter anderem in der Figur der „ausschließende[n] Einschließung" (Esposito 2004, 15). Im Falle Agambens wird sogar von einer ursprünglichen politischen Struktur des Abendlandes gesprochen, welche den Ausschluss aus einer Rechtsgemeinschaft in Form einer „einschließende[n] Ausschließung" erbringt (Agamben 2002, 17).

\section{Biopolitik nach Agamben und Esposito}

Agamben hält die „Produktion eines biopolitischen Körpers“ in der politischen Geschichte des Abendlandes für „die ursprüngliche Leistung der souveränen Macht“ (Agamben 2002, 16). Eine souveräne Macht, die demnach ab ovo eine biopolitische Ordnung konstituiert, indem sie einen Rechtsraum institutionalisiert, mit dem zugleich bestimmtes Leben auf den Status der zoé im aristotelischen Sinne reduziert wird (vgl. Flügel-Martinsen 2011, 28f.). Dieses ausgeschlossene „nackte Leben“ befindet sich in keiner politischen Ordnung, besitzt keine soziokulturelle Lebensform ${ }^{10}$ und ist einzig auf die naturhaften Funktionen des Lebens selbst bezogen - ,reine[s] Sein“ (Agamben 2002, 191). „Nacktes“, bloßes Leben wird nun insoweit einschließend ausgeschlossen, als die eigentliche Konstitution einer jeden politisch-rechtlichen Ordnung laut Agamben mit einem souveränen Bann des jeweilig nackten Lebens aus der politischen Ordnung koinzidiert (vgl. Agamben 2002, 148). Dies bedeutet, dass der Status von nacktem Leben konstitutiv an den souveränen Bann gebunden ist, der einen Raum der Ausnahme gegenüber der rechtlichen Ordnung und den zu schützenden Lebensformen schafft. Insofern kann von der paradoxalen Figur der "einschließenden Ausschließung“ die Rede sein. ${ }^{11}$

10 In seinem Essay Lebens-Form verdeutlicht Agamben den Unterschied zwischen dem „bloßen“ biologischen Leben und den Lebensformen, die in ,juristisch-sozialen Identitäten abstrakt kodifiziert werden“ (Agamben 1994, 253). Agamben nennt beispielhaft die Lebensformen des Rentners, des Studenten, des Lohnempfängers, des Journalisten oder der Eltern.

11 Jene „originäre politische Beziehung“ (Agamben 2002, 190) ist nach Peter Zeillinger zudem alteritär zu verstehen (vgl. 2020, 16). Im Kontext der „einschließenden Ausschließung “ bedeutet dies, vereinfacht gesagt, ein konstitutives Verhältnis, in dem das nackte Leben innerhalb der politischen Ordnungen als Konstitutionsbedingung derselben zum Ausdruck kommt. Auch für das 
Zwar setzt Agamben anders als Foucault den Beginn der Biopolitik bereits sehr viel früher an (vgl. Agamben 2002, 190), dennoch verändert sich laut Agamben der biopolitische Bezug auf das Leben mit der Moderne zunehmend. Die Herbeiführung eines Ausnahmezustandes wird nach Agamben ab dem 18. Jahrhundert zusehends zur Regierungstechnik souveräner Macht, worauf eine Tendenz zur Ununterscheidbarkeit politisch-rechtlicher Kategorien, wie etwa derjenigen zwischen der Sphäre des Öffentlichen und des Privaten sowie das Aussetzen von Lebensformen und subjektiven Rechten, folgen soll (vgl. Agamben 2002, 14, 19, 130; vgl. Agamben 2004, 39). In dieser Hinsicht sind Agambens umstrittene Aussprüche zu verstehen, die das Lager zum „absoluten Ausnahmeraum“ (Agamben 2002, 30), zum Paradigma $^{12}$ moderner Politik erkoren (vgl. Agamben 2002, 131) und eine Wesensähnlichkeit zwischen Demokratie und Totalitarismus artikulieren (vgl. Agamben 2004, 9; vgl. Agamben 2002, 20f., 130). Zusammenfassend kennzeichnet die biopolitische Moderne aus der Perspektive Agambens, dass praktisch jede*r Bürger*in als potenziell nacktes Leben gehandelt wird (vgl. Agamben 2002, 148, 121). Oder anders formuliert, nach Agamben fallen das „Innen“ und „Außen“ politischer Ordnungen schrittweise zusammen.

Theoretische Differenzen zu Foucaults Modell der Biopolitik scheinen in Anbetracht der obigen Erläuterungen zu Agamben augenscheinlich und werden in der Forschungsliteratur ausführlich diskutiert. ${ }^{13}$ Für die vorliegende Abhandlung von besonderem Interesse ist das sich unterscheidende Verständnis souveräner Macht, der beide Denker innerhalb ihrer biopoliti-

nackte Leben bildet umgekehrt die politische Ordnung die alteritäre Konstitutionsbedingung.

Agambens Verständnis eines Paradigmas wird in seiner Schrift Signatura rerum (2009) dargelegt. Demnach löst sich im Begriff des Paradigmas das einzelne historische Beispiel, um eine Regelhaftigkeit oder Struktur sichtbar zu machen (vgl. Agamben 2009, 29; vgl. Zeillinger 2020, 8). Dahingehend ist auch Agambens Beispiel des Lagers zu kontextualisieren.

13 Zum Vergleich der verschiedenen Lebensbegriffe vgl. Muhle (2007). Die Kritik an Agambens Modell im Verhältnis zu Foucault fasst wiederum Lemke zusammen: Er kritisiert Agambens Art und Weise, die Biopolitik als historisches Phänomen preiszugeben (vgl. 2004, 959). Weiterhin übt Lemke Kritik an der fehlenden Differenzierung von unterschiedlichem nacktem Leben (vgl. 2004, 952, 957). Die Einschätzung Lemkes, dass Agamben den biopolitischen Steigerungsaspekt des Lebens unterschlägt, teilen zudem sowohl Sarasin (2003, $58)$ als auch Muhle $(2007,88)$. 
schen Konzeptionen einen zentralen Platz einräumen. Während Agamben eine „Strukturtheorie des Politischen auf der Grundlage der Logik der Souveränität“ in der Auseinandersetzung mit Carl Schmitt und Walter Benjamin entwirft (Lemke 2004, 946), unterstreicht Foucault die Gebundenheit der Biopolitik an eine bestimmte Wissensform des 18. und 19. Jahrhunderts, infolge der sich die neue Regierungsform herausbildet, die dem Machttypus der Bio-Macht entspricht. Damit rückt die Souveränitätsmacht nach Foucault in den Hintergrund; sie wird sekundär, vergegenwärtigt sich jedoch in der Fragmentierung des Bevölkerungskörpers. Während Agamben die Bio-Macht einzig am souveränen Bann des nackten Lebens entwickelt (vgl. Reuschling 2006, 70), interessiert Foucault gerade der Aspekt der produktiven Lebensbeförderung, den dieser spezielle Machttypus der Bio-Macht mit sich bringt und den Agamben eindrücklich verkennt (vgl. Sarasin 2003, 58; vgl. Lemke 2004, 952, 957). Welche Implikationen diese theoretische Divergenz besitzt, wird im Anschluss an die Darstellung der Biopolitik nach Esposito erörtert.

Esposito kontrastiert Foucaults Überlegungen zur Biopolitik mit dem „Paradigma der Immunisierung“, das mit dem Beginn der Moderne an Bedeutung gewinne (vgl. Esposito 2010, 98). Biopolitische Maßnahmen lassen sich als eine die Bevölkerungsgemeinschaft vor Übel - wie etwa einem pandemischen Virus - schützende Immunisierung zur „Erhaltung des Lebens“ deuten (vgl. Esposito 2014, 337). Das Gemeinschaftliche, die „Communita$\mathrm{s}$ " ${ }^{14}$ kennzeichnet hierbei per definitionem eine Verbundenheit einzelner Individuen über das gemeinsame „munus“ - eine soziale Pflicht, Schuld oder auch Last (vgl. Esposito 2004a, 15). Konkret bietet die biopolitische Immunisierung Schutz, indem auf das nackte, biologische Leben der Gemeinschaft zugegriffen wird (vgl. Esposito 2004b, 23). ${ }^{15}$ Analog zur Logik des Impfens

14 Nach Esposito steht die Immunitas zunächst der Communitas gegenüber. Letztere bedeute so viel wie das Teilen einer Pflicht (vgl. Esposito 2004a, 15). Die Immunisierung der Gemeinschaft oder des Individuums nennt Esposito „Immunitas“. Diese wird dagegen als eine „Abhebung von der Lage anderer“, als Kündigung der Pflichten und Laster des Gemeinschaftlichen verstanden (Esposito 2004b, 13), was nach Esposito im Grunde einem antigemeinschaftlichen Zug entspricht. Dennoch gibt er zu bedenken, dass immunitäre Schutzfunktionen jeder Gemeinschaft eigen sind und daher nicht von einem starken Gegensatz auszugehen ist (vgl. Esposito 2002b, 26).

15 Hinzuzufügen ist, dass das Immunisierungsparadigma auch die einfache, direkte Ausgrenzung von Menschen kennt, die für die Gemeinschaft eine Gefahr 
versteht sich dabei die Reduktion der soziokulturellen Lebensformen auf den „nackten biologischen Gehalt“ als ein notwendiges Übel (Esposito 2004b, 23). Denn die besagte Reduktion wird temporär in Kauf genommen - das Übel der Reduktion des Lebens auf sein biologisches Substrat wird „hereingenommen“, in den kollektiven Körper der Bevölkerung eingeschlossen (vgl. Lorey 2011, 26off.) -, um der Gemeinschaft längerfristig Schutz zu bieten und die soziokulturellen Formen des Lebens dauerhaft zu bewahren. In ebendiesem Sinne spricht Esposito vom „strukturell aporetischen Charakter der immunitären Prozedur" (Esposito 2004b, 16), die sich zugleich mit der Begriffskonstellation der „ausschließenden Einschließungen“ bestimmen lässt (vgl. Esposito 2004b, 14ff.). ${ }^{16}$

Obgleich dem Leben als „Gegenstand der Immunisierung“ (Esposito 2004b, 16) Schutz geboten wird, vermag die Biopolitik ebenso in eine autoimmune Reaktion umzuschlagen, die das kollektive Leben der Bevölkerung gefährdet und vor der Esposito in seinem Beitrag zur Corona-Pandemie warnt (vgl. Esposito 2020). Demgemäß äußert Esposito, dass eine „Immunisierung in hohen Dosen“, gemeint sind überbordende Schutzmechanismen, einen gegenteiligen Effekt induziert, und zwar die andauernde „Reduktion des [qualifizierten] Lebens auf sein nacktes biologisches Substrat“ (Esposito 2010, 97). In diesem Sinne finden beide zentralen Funktionen der Biopolitik nach Foucault, sowohl die produktive Lebenssteigerungsfunktion als auch die negativ ausgrenzende Funktion, im Immunisierungsparadigma ihre Entsprechung (vgl. Esposito 2014, 338; vgl. Gorgoglione 2016, 18).

\section{Problematik der Biopolitik}

Wie aus den drei angeführten Positionen zu entnehmen ist, lassen sich nur bedingt allgemeine Kriterien für die Beschreibung der Biopolitik definieren. Ein potenzielles gemeinsames Merkmal, das sowohl Agamben, Esposito als

darstellen (vgl. Gorgoglione 2016, 18). Zu weiteren Figuren des Immunen vgl. Lorey (2011).

16 Esposito denkt das Immunisierungsparadigma zwar als spezielles Phänomen der Moderne, doch bestätigt er zugleich, dass die Politik bereits früher auf das Leben bezogen war (vgl. Esposito 2014, 346). Mit der Moderne findet sich das Immunisierungsdispositiv nach Esposito in zahlreichen Disziplinen und Gesellschaftsbereichen wie dem Recht, der Medizin, der Anthropologie oder der Theologie wieder und beschränkt sich daher nicht vorwiegend auf die Gesamtheit einer Bevölkerung oder Gemeinschaft (vgl. Esposito 2002b). 
auch Foucault teilen, sind die Ein- und Ausschlussmechanismen biopolitischer Praxis. Doch selbst in Anbetracht dieser Gemeinsamkeit ist es erforderlich, Differenzierungen zwischen Foucault und den Positionen Agambens und Espositos zu treffen:

Sowohl Agamben als auch Esposito operieren im Kontext der Einund Ausschlussmechanismen (bio)politischer Ordnungen mit dem Begriff des nackten Lebens, worin beide die Reduktion auf ein rein biologisches Leben ohne rechtliche oder andere Formen verstehen, über das die „souveräne Macht“ verfügt. Hingegen hat in den Überlegungen Foucaults das nackte Leben einzig insofern eine minimale Entsprechung, als mit dem Begriff auch basale Eigenschaften des Lebens wie die Gesundheit oder die Sterblichkeit im Wissenskomplex der Biologie und Medizin tangiert werden. ${ }^{17}$ Soziale Distanzierung, die Verpflichtung zum Tragen von Masken, Heimquarantäne und Ausgangssperren, das Schließen nationaler Grenzen und zuletzt die Impfpraxis - all diese aktuell gebliebenen Regierungsmaßnahmen implizieren jedenfalls die Anwendung von Wissensformen, die auf Charakteristika des Biologischen der Gattung Mensch rekurrieren, um dadurch zum Beispiel ein pandemisches Virus in Schach zu halten. Hält der Soziologe Andreas Folkers (2020) einzelne Maßnahmen im Anschluss an Esposito für durchaus berechtigt und zumutbar, um im Sinne eines solidarischen Aktes den längerfristigen Schutz der Gesamtheit einer Bevölkerung vor dem Coronavirus zu gewährleisten, kritisiert Agamben (2020) derartige behördliche Vorschriften als eine ungerechtfertigte Beschränkung von Freiheiten, wie in der Einleitung bereits erwähnt.

Ungeachtet der Abwägung, welche Maßnahmen tatsächlich berechtigt sind, stellt sich weiterhin die Frage nach der mangelnden Differenzierung im Umgang mit dem Begriff des „nackten Lebens“. Bedeutet der derzeitige gesellschaftliche Ausnahmezustand in Folge der Corona-Pandemie nicht eine temporäre und gezielte Reduktion auf nackte, biologische Tatsachen, wohingegen andere Bereiche des Lebens weiterhin geformt und rechtlich geschützt bleiben? Wo lassen sich demnach mit der Aussage Agambens über die zunehmende Ununterscheidbarkeit zwischen dem Innen und dem Außen biopolitischer Ordnungen sowie dem damit einhergehenden Verlust an Freiheitsrechten Differenzierungen erkennen?

17 Konzise differenziert Maria Muhle die verschiedenen Lebenskonzepte Foucaults und Agambens (vgl. Muhle 2007, 87). 
Im Kontrast dazu tritt hingegen mit Foucaults Versuch, das Konzept der Biopolitik an die Genealogie des Liberalismus anzunähern, deutlich zu Tage, dass eine Politik, die auf das biologische Leben der Bevölkerung abzielt, nicht zwangsläufig mit Freiheitsrechten kollidieren muss (vgl. Foucault 2006). Das Gegenteil ist der Fall, denn Foucault gibt zu bedenken, dass der Schutz des Lebens mittels Dispositiven der Sicherheit geradewegs ökonomischen und allgemein biopolitischen Kalkülen folgt sowie historisch betrachtet zuallererst eine institutionalisierte Form der bürgerlichen Freiheit herstellt. ${ }^{18}$ Zudem nimmt Foucault den Agamben'schen Vergleich zwischen demokratischem und totalitärem Staat vorweg und kritisiert eine derartige Parallele als inflationär (vgl. Foucault 2006, 263ff.). ${ }^{19}$

Eines der zentralen Versäumnisse von Agamben und Esposito ist es meines Erachtens, die Möglichkeit des Widerstandes gegen biopolitische Maßnahmen von Seiten der auf scheinbar nacktes Leben reduzierten Regierten nicht zu thematisieren. Der Grund hierfür liegt in den Konzeptionen der Biopolitik selbst, da diese einzig über die Modi der Ein- und Ausschließung eine politische Ordnung konstituiert sehen und hierdurch außerdem performativ fixieren, wie dies in Rekurs auf Judith Butlers Kritik an Agamben konstatiert werden kann (vgl. Butler 2016, 106). Hierbei handelt es sich um eine Fixierung, die sich nicht zuletzt in der Rede von einer „Paradoxie“ oder „Aporie“ der Biopolitik nach Gorgoglione und Esposito offenbart, insoweit die Biopolitik in sich genau zwei konträre Funktionen vereint - die Steigerung und Ausgrenzung respektive Tötung des (nackten) Lebens.

Dieser Sachverhalt korrespondiert unterdessen mit der zugeschriebenen Rolle der souveränen Macht, die Esposito ebenso wie Agamben als die genuine Kraft zur Durchsetzung biopolitischer Maßnahmen bewertet (vgl.

18 Dabei bespricht Foucault jedoch eine gewisse Ambivalenz im Zuge der liberalen Einsetzung von Freiheit im Europa des 18. Jahrhunderts. Einerseits handelt es sich bei diesen Freiheitsrechten um Freiheiten, die einem Nützlichkeitskalkül folgen, indem die Freiheit des Marktes mittels der Freiheit der Individuen sichergestellt werden soll. Andererseits beschreibt Foucault auch ein Wechselspiel des Nützlichkeitskalküls mit dem „Ansatz der Revolutionäre" (Foucault 2006, 66), der die Freiheitsrechte primär mit Berufung auf unveräußerliche Menschenrechte fordert (vgl. Foucault 2006, 67ff.).

Bereits Walter Reese-Schäfer vergleicht in dieser Hinsicht die Positionen Agambens und Foucaults. Er kritisiert Agamben dafür, dass eine allzu inflationäre und gar staatsphobische Haltung die Austauschbarkeit der Analysen befördert (vgl. Reese-Schäfer 2009, 123f.). 
Esposito 2014, 352f.). In den Worten Agambens ist es mithin jene souveräne Macht, welche die Menschen zu regieren weiß, indem sie zuvörderst einen Raum des Rechts schafft und zugleich nacktes Leben verbannt. Auch hier findet sich die binäre Logik des Einschlusses und Ausschlusses wieder, die es erschwert, biopolitisch regierte Menschen in Zeiten der Corona-Pandemie sowie grundsätzlich ausgeschlossenes, nacktes Leben als immer schon handlungsfähige und politisch widerständige Menschen kenntlich zu machen (vgl. Butler 2016, 108f.).

Mit dem ausschließlichen Interesse an der Struktur des Biopolitischen - ein Umstand, den Peter Zeillinger im Falle Agambens dezidiert unterstreicht (vgl. Zeillinger 2020, 2, 6) - gelingt es Agamben und Esposito überdies nicht, die Unterschiede zwischen verschiedenartig ausgeschlossenen Menschen zu konkretisieren (vgl. Lemke 2004, 956): Geflüchtete Personen, die rezent ohne Rechtschutz und Zukunftsperspektiven auf griechischen Inseln innerhalb der EU festsitzen, werden von Politiker*innen in Österreich augenscheinlich als potenzielle Gefahr für die Bevölkerung eingeschätzt, da das mögliche Potenzial zur gesellschaftlichen Integration bereits überschritten sei. ${ }^{20}$ Dieses eindringliche Beispiel gegenwärtiger biopolitischer Exklusion unterscheidet sich jedoch deutlich von biopolitischen Maßnahmen im Kontext der Corona-Krise. Aus diesem Grund ist auch hier eine Differenzierung anzudenken, die im Falle Agambens und Espositos unter den Tisch zu fallen droht.

Im Anschluss an Foucault kann wiederum zwischen einer grundlegenden „rassistischen“" ${ }^{21}$ Fragmentierung des Bevölkerungskörpers und den biopolitischen Maßnahmen zum Lebensschutz sowie der Lebenssteigerung einer Bevölkerung unterschieden werden. Es ist Philipp Sarasin, der im März des Jahres 2020 dahingehend eine Kritik an der „semantischen Keule“ der Biopolitik äußert, die ihm unzureichend erscheint, um die gegenwärtige Corona-Krisensituation zu erfassen (Sarasin 2020; vgl. Sarasin 2019, 11).

20 Derart argumentiert Integrationsministerin Susanne Raab in einem ZIB-2-Interview mit Martin Thür im Österreichischen Rundfunk am 30.8.2020. Vgl. hierzu thematisch einen Beitrag von Katrin Meyer und Patricia Purtschert zu biopolitischer Sicherheit im Kontext des Migrationsmanagements (2008).

21 Hierzu wäre kontemporär ein Verständnis kulturellen „Rassismus“ nach Stuart Hall oder Étienne Balibar zu ergänzen. Auch betont Laufenberg in diesem Sinne, dass Foucaults Rassismusbegriff nicht notwendig mit dem biologischen „Rasse“-Begriff korrelieren muss (vgl. Laufenberg 2016, 28). Vgl. ebenfalls Fußnote 9. 
Anhand des von Foucault in einigen seiner Schriften angeführten idealtypischen Seuchenmodells, das den gesellschaftlichen Umgang mit unterschiedlichen Krankheitserregern und den daraus resultierenden Krankheitsbildern wie der Lepra, der Pest oder der Pocken historisch nachzeichnet, versucht Sarasin die rezenten Reaktionen auf die Krisensituation zu begreifen. Bereits seit dem 18. Jahrhundert wurde in weiten Teilen Europas und Nordamerikas versucht, die Pockeninfizierten statistisch zu vermessen, Risikoabwägungen durchzuführen, Sterblichkeitsraten zu erstellen, Quarantänemaßnahmen durchzusetzen und Impfpraktiken anzuwenden, um die Pandemie einzudämmen (vgl. Foucault 2004, 25f.; vgl. Sarasin 2005). Die Parallelen zur Corona-Pandemie sind demnach augenscheinlich.

Trotz der Kritik Sarasins am Begriff der Biopolitik bin ich der Ansicht, dass die Rede von der Biopolitik nicht aufgegeben werden muss, zeigt der Begriff doch gerade die Verbindungslinien zwischen dem biologischen Wissen über das Leben und den mit diesem Wissen operierenden Regierungsmaßnahmen auf. ${ }^{22}$ Mein Vorschlag lautet an dieser Stelle vielmehr, das Verständnis der Gouvernementalität ins Spiel zu bringen. Im Unterschied zur primär struktural verstandenen Biopolitik nach Agamben und Esposito richtet der Begriff der Gouvernementalität die Aufmerksamkeit auf spezielle Regierungspraktiken, wie am Beispiel der Pocken veranschaulicht. Dadurch eröffnet sich ein Terrain, in dem das Regieren von Menschen stets als eine Praxis zu erachten ist, der potenziell Widerstand entgegenwirkt. Diese Sichtweise wird wiederum verständlich, insoweit Foucaults Analytik der Macht ernst genommen wird: Macht ist laut Foucault ausdrücklich relational zu denken und exakt in diesem Sinne muss sie ausnahmslos über Formen des Widerstandes formuliert werden (vgl. Foucault 1976, 96). Darüber hinaus wird das Paradigma des Regierens in Foucaults späteren Schriften selbst als „Leitfaden“ für die Machtanalyse gebraucht (vgl. Lemke, Krasmann und Bröckling 2000, 8). Ergänzend zur Geschichte der Gouvernementalität wird also Foucaults Machtanalyse selbst durch den Raster der Gouvernementalität betrachtet.

22 In einem aktuellen Beitrag von Paul Preciado (2020) wie auch in einem einführenden Text von Gerhard Unterthurner (2016, 172ff.) wird das epidemiologische Modell Foucaults bewusst mit dessen Ausführungen zur Biopolitik verknüpft. Beide Autor*innen sehen also wie ich selbst kein Problem darin, die gegenwärtigen politischen Maßnahmen unter den Begriff der Biopolitik zu summieren. 


\section{Regieren als Paradigma der Machtanalytik Foucaults}

Wo kann nun mit Foucault ein bestimmtes Moment des Widerstandes und der Kritik an biopolitischen Regierungspraktiken lokalisiert werden? Diese Fragestellung leitet die folgenden Überlegungen. Der erste Schritt zur Beantwortung liegt darin, nochmals zu akzentuieren, dass die Biopolitik spätestens seit den Vorlesungen zur Geschichte der Gouvernementalität selbst als eine Regierungsform zu verstehen ist, die verschiedene Regierungstechnologien vereint. Anders als in der Vorstellung Agambens, der die Biopolitik mit der souveränen Macht kurzschließt, begreift Foucault die „Regierung der Menschen“ (Foucault 2004, 520) als eine in Europa erwachsende Praxis, die seit dem 16. Jahrhundert in den Überlegungen zur „Kunst des Regierens“ bei Machiavelli, in der pastoralen Macht der christlichen Kirchen und den Polizeiwissenschaften des 17. und 18. Jahrhunderts verschiedene Vorläufer hat (vgl. Foucault 2004, 165). Am Ende der einzelnen Entwicklungslinien steht sodann die Idee der Gouvernementalität, für welche Foucault in der vierten Einheit der Vorlesungsreihe Sicherheit, Territorium, Bevölkerung (2004) eine kompakte Definition anbietet:

Ich verstehe unter „Gouvernementalität“ die aus Institutionen, den Vorgängen, Analysen und Reflexionen, den Berechnungen und den Taktiken gebildete Gesamtheit, welche es erlauben [sic], diese recht spezifische, wenn auch sehr komplexe Form der Macht auszuüben, die als Hauptzielscheibe die Bevölkerung, als wichtigste Wissensform die politische Ökonomie und als wesentliches technisches Instrument die Sicherheitsdispositive hat. (Foucault 2004, 162)

Das Sicherheitsdispositiv versteht sich als eine Gesamtheit an Maßnahmen, um die Bevölkerung anhand von Statistiken und konkreten Wahrscheinlichkeitsberechnungen derart zu regulieren, dass wirtschaftliche Prozesse und der Lebensschutz der Bevölkerung gewährleistet sind. Hierbei spielen die sich im 18. Jahrhundert entwickelnde politische Ökonomie sowie die Idee des Liberalismus als sich selbst begrenzende Regierungsform zur Freisetzung der Marktmechanismen wie auch zur Steigerung ökonomischer Profitraten eine entscheidende Rolle. ${ }^{23}$ Es ist gerade dieses ambivalente Terrain

23 In den Vorlesungen von 1979 führt Foucault Formen des Liberalismus in zentraler Hinsicht mit der Gouvernementalität eng. Aus diesem Grund unterscheidet Lemke auch zwischen einer allgemeinen und einer substanziellen Gebrauchsweise der Gouvernementalität nach Foucault (vgl. Lemke 
zwischen individueller Freiheit und der Sicherheit einer Bevölkerung, in dem sich Agamben und Esposito thematisch bewegen. Doch anders als Agamben und Esposito präzisiert Foucault die Verbindung zwischen Sicherheit und Freiheit als ein historisch gewachsenes Bedingungsverhältnis (vgl. Foucault 2006, 97). ${ }^{24}$ Die Abwägung kollektiver Interessen gegen individuelle Interessen besitzt folglich eine andauernde Geschichte (vgl. Foucault 2006, 100).

Folgen wir Foucault, so wird die zunehmende Gouvernementalisierung im 18. und 19. Jahrhundert mit einem neuen Wissenskomplex konfrontiert. Es ist jenes Wissen über das Leben, das sich mit einer Macht über das Leben verzahnt - der bereits erwähnten Bio-Macht. Machtanalytisch betrachtet gliedert sich die Foucault'sche Biopolitik also in die sich bereits seit dem 17. Jahrhundert entfaltende Bio-Macht ein (vgl. Foucault 1996, 285, 295f.). Es handelt sich dabei um einen Machttypus, der die in Überwachen und Strafen (1994) indizierte Disziplinarmacht aufnimmt, nach Gerhard Unterthurner zudem erweitert (vgl. 2016, 166) und sowohl auf der individuell-körperlichen Ebene subjektkonstituierend als auch eben biopolitisch auf ein Kollektiv, die Bevölkerung, wirkt (vgl. Foucault 1976, 135; vgl. Foucault 1996, 286f., 299). Für das Konzept der Biopolitik bedeutet die Hinwendung zum Begriff der Gouvernementalität folglich keine einfache Ablösung. Als biopolitische Gouvernementalität, in der sich das biologische Wissen um die Gattung Mensch reflektiert, erweitert sich das Verständnis der Biopolitik um die übergeordnete, allgemeinere Kategorie der Gouvernementalität.

Petra Gehring unterscheidet exemplarisch zwischen Biopolitik und Bio-Macht, insoweit sie ersteren Begriff unter den Mantel bewusster Kalküle einer „Politikerpolitik“ subsummiert (Gehring 2006, 14). Die Bio-Macht ist hingegen, konzise gesagt, jene Machtform, die dem biologischen Wissen

1997, 194). In analytischer Weiterführung wird mit letzterer die liberale bzw. neoliberale Gouvernementalität zum primären Untersuchungsgegenstand Foucaults. Dennoch ist es mir in dem gewählten Rahmen auch aus Gründen der Stringenz ein Anliegen, vorrangig mit der allgemeinen Verwendungsart zu arbeiten, die es erlaubt, das Konzept der Gouvernementalität ebenso auf andere Formen der Regierung und in Bezug auf andere Weltregionen zu applizieren. Es bleibt ebenso anzumerken, dass Foucault nur ansatzweise die Verbindungslinien zwischen Gouvernementalität, Liberalismus und Biopolitik herausgearbeitet hat (vgl. Foucault 2006, 435, 443).

24 Vgl. hierzu thematisch einen Beitrag von Alex Demirovic, in welchem er dem „liberalen Dilemma“ zwischen Sicherheit und Freiheit auf den Grund geht (2008). 
Rechnung trägt, dass der Mensch einer Gattung angehört (vgl. Foucault 2004, 13). Indes ist kritisch zu bemerken, dass Foucault unter „Regierung“ keineswegs einzig eine Regierung im Sinne gewählter Politiker*innen begrifflich zu erfassen sucht (vgl. Foucault 2020, 29f.). Dies wird in einem Interview mit Ducio Trombadori augenscheinlich, in dem Foucault unter „Regierung“ die „Gesamtheit der Institutionen und Praktiken, mittels derer man die Menschen lenkt, von der Verwaltung bis zur Erziehung" versteht (Foucault 1980, 116). ${ }^{25}$ Einzelne Regierungstechniken oder -technologien werden von Lemke im Anschluss an Foucault hilfreich als „systematisierte, regulierte und reflektierte Formen der Machtausübung" bestimmt (Lemke 2001, 119), die gerade nicht bloß verfasste Gesetze und die höchsten Politikämter leisten, sondern einem ganzen Apparat an Personen, Institutionen und Vereinen zuzuordnen sind.

Der grundlegende Wortsinn des Begriffs der „Regierung“ erschließt sich Foucault interessanterweise über die Bedeutung der Ausübung von Macht. Auf diesen basalen Zusammenhang stellt Foucault in einem Text aus dem Jahre 1982 mit dem Titel Subjekt und Macht ab. Seine nachfolgend zitierten Ausführungen zur Bestimmung von Machtbeziehungen lassen erkennen, dass der Begriff der Macht an ein Verständnis des Regierens gekoppelt wird:

Der für Macht typische Beziehungstyp ist daher nicht im Bereich der Gewalt und des Kampfes zu suchen und auch nicht im Bereich des Vertrags und der freiwilligen Bindung [...], sondern im Bereich jenes einzigartigen, weder kriegerischen noch juristischen Handlungsmodus, den das Regieren darstellt. (Foucault 1982, 256)

Infolgedessen bedeutet Macht auszuüben und Menschen zu regieren die Strukturierung des möglichen Handlungsfeldes anderer Subjekte (vgl. Fou-

25 Aber auch die Weisen der Selbstführung werden mit dem Begriff der Gouvernementalität bereits thematisiert und in späteren Vorlesungen virulent. Somit reicht das Kontinuum des Regierens nach Lemke „von der ,Regierung des Selbst ' bis zur ,Regierung der anderen“ (Lemke 2000, 33). Streng genommen lässt sich also nochmals zwischen dem allgemeineren Begriff des Regierens, unter den auch die Leitung der Familie, der Kinder oder des Selbst fällt, von dem Konzept der Gouvernementalität differenzieren, mit dem bereits eine bestimmte politische Form mitgedacht ist (vgl. Lemke 2016, 487). Für eine einschlägige Einführung in den Begriff der Gouvernementalität und des Regierens nach Foucault vgl. Lemke 2016. 
cault 1982, 256). Mit dem Begriff des „Regierens“ gewinnt Foucault somit einen neuartigen Gesichtspunkt innerhalb seiner Machtanalyse, dem es gelingt, eine allgemeine, „quasi-generalisiert[e]“ Eigenschaft von Machtbeziehungen begrifflich auszulegen (Saar 2009, 583). Damit werden die historischen Analysen unterschiedlicher Machttypologien nicht ausgesetzt, viel eher eröffnet sich ein Horizont, dem drei wesentliche Einsichten attestiert werden können.

Erstens verlieren die Zuschreibungen an die Macht zusehends ihren repressiven, substanziellen Charakter, wie dieser noch stellenweise in Überwachen und Strafen (1994) sowie in Die Ordnung des Diskurses (2001) präsent ist, um rückwirkend eine produktive und strategische Form anzunehmen (vgl. Ruoff 2018, 168f.). Letzteres geschieht maßgeblich in Der Wille zum Wissen (1976). Zweitens wird eine durchgängige Beschreibung von Machtbeziehungen möglich, die Foucault zwar nicht als Theorie erfasst, jedoch zumindest als ein „begriffliche[s] Erfordernis[s]“ einstuft (Foucault 1982, 241). ${ }^{26}$ Drittens grenzt sich der Machtbegriff deutlich vom Topos der Herrschaft ab: Wird Macht in einer Machtbeziehung immerzu einseitig induziert, so erstarrt jene Beziehung nach Foucault. Sie wird unbeweglich und es kann von einer Herrschaftsbeziehung gesprochen werden (vgl. Foucault 1984a, 276f.). Innerhalb einer Herrschaftsbeziehung sind Widerstandspraktiken kaum möglich und werden unterdrückt. Zu regieren ist im Sinne Foucaults folglich nicht mit (souveräner) Herrschaft zu verwechseln (vgl. Foucault 2004, 173; vgl. Lemke 2001, 119).27

26 Foucault vermeidet es, von einer Theorie der Macht zu sprechen, da nach seiner Ansicht jede Theorie vorweg ein ahistorisches Objekt setzt (vgl. Foucault 1982, 241). Für Foucault ist es also von Bedeutung, keine Theorie vorab einfach anzuwenden, sondern über die historischen Analysen verschiedener Praktiken und Entwicklungen einen Begriff der Macht zu denken, der mithin ggf. „eine Theorie der Macht in Gang setzt“ (Foucault 2004, 14).

27 Erstmalig differenziert Foucault die Verhältnisse der Macht von dem Phänomen der Herrschaft in seiner Vorlesungsreihe In Verteidigung der Gesellschaft (1996). Hier gesteht Foucault zudem ein, dass die „Hypothese Nietzsches“, also die Untersuchung der Macht am Leitfaden des Krieges und des Kampfes, der seine Idee der Macht in den Jahren zuvor maßgeblich bestimmt hatte, ungenügend ist, um dem Facettenreichtum der zwischenmenschlichen Machtbeziehungen Rechnung zu tragen (vgl. Foucault 1996, 33ff.). 


\section{Macht und Widerstand}

Wird nun mit Foucault unter der Regierung nicht bloß ein souveräner Machtapparat im Sinne Agambens erfasst (vgl. Scheu 2014, 60), sondern ein vielseitig vernetztes Beziehungsgeflecht der Macht beschrieben, so gelingt es, eine Analyse der „Makromächte“, zu denen etwa der Staat gehört, mit so genannten „Mikromächten“ in Beziehung zu setzten (vgl. Foucault 2004, 514) ${ }^{28}$ Mikromächte wirken gerade zwischen einzelnen Menschen. Im Kontext der Corona-Krise kann diese Mikroebene der Machtbeziehungen am Beispiel der Beziehung zwischen Ärzt*innen und Patient*innen oder etwa zwischen der Polizei und der Bevölkerung veranschaulicht werden. Exemplarisch konfrontieren also sowohl Ärzt*innen, Virolog*innen oder Epidemiolog*innen als auch die Polizei die Bürger*innen mit Formen des Wissens, die strategisch auf das Verhalten der Menschen wirken sollen, um in unserem Beispiel die Eindämmung des Virus zu erleichtern.

Diese Verbindung zwischen der Makro- und der Mikroebene der Machtanalyse stellen Agamben und Esposito wiederum nicht her. Sie verbleiben demgegenüber auf einer strukturellen Makroebene, ohne sich die tatsächlichen Praktiken vor Augen zu führen, die politische Ordnungen erst konstituieren. Aus diesem Grund versäumen sie es des Weiteren, die zahlreichen „Widerstandspunkte“ gegen etablierte politische Ordnungsstrukturen sowie konkrete biopolitische Maßnahmen zu konzeptualisieren (vgl. Foucault 1976, 96). Mit dem alleinigen Blick auf die Struktur politischer Ordnungen, die Agamben und Esposito qua Mechanismen der „einschließenden Ausschließung“ respektive „ausschließenden Einschließung“ identifizieren, wird die genuine Heterogenität politischer Ordnungen verkannt. Diese Heterogenität kann im Sinne Foucaults dadurch erklärt werden, dass die Ausübung von Macht potenzielle Widerstände induziert, wie er in seinem Vortrag Omnes et singulatim ein weiteres Mal bekräftigt (vgl. Foucault 1979, 218). Daraus folgt meines Erachtens die Einsicht, dass Praktiken des Regierens zwar Einschlüsse und Ausschlüsse tätigen und hierdurch politische Ordnungen begründen, letztere jedoch konstitutiv in einem vorgeschobenen Feld verschiedener Kräfteverhältnisse angesiedelt sind und bleiben.

28 „Tatsächlich läßt sich eine Analyse in Begriffen von Mikromächten ohne Schwierigkeit mit der Analyse von Problemen wie dem der Regierung und des Staates verknüpfen“, die Foucault als die „Ebene der Makromacht“ begreift (Foucault 2004, 514). 
Ausdrücklich hält Foucault bereits 1976 in Der Wille zum Wissen die Anbindung der Macht an die Widerständigkeit fest. Die Verortung der Macht als „die Vielfältigkeit von Kräfteverhältnissen, die ein Gebiet bevölkern und organisieren“, drückt geradewegs die Eigentümlichkeit der Beziehung zwischen Macht und Widerstand aus (Foucault 1976, 93; vgl. Foucault 1976, 96): Foucault spricht von einem Verhältnis der Kräfte, die sich auf mikrologischer wie makrologischer Ebene gegenseitig stützen sowie insbesondere im Widerstreit zueinander stehen können - derart lassen sich nach Foucault Machtbeziehungen definieren. Zusammengefasst bleibt die Regierung der Menschen und die Ausübung von Macht „ohne potentielle Weigerung oder Auflehnung“ unverständlich (Foucault 1979, 218).

\section{Kritik des Regierens}

Wenn es so ist, wie Foucault sagt, dass die Machtbeziehungen zwischen den Menschen seit der Neuzeit stetig „gouvernementalisiert“, „das heißt, in der Form oder unter den Auspizien der staatlichen Institutionen elaboriert, rationalisiert und zentralisiert werden“ (Foucault 1982, 26of.), lässt sich sodann schlussfolgern, dass der Widerstand gegen Regierungsmaßnahmen im Ausgang der Neuzeit aus der Beziehung der Gouvernementalität zur Bevölkerung immanent abgeleitet werden kann. Denn die Machtausübungen biopolitischer Regierungsmaßnahmen konstituieren eigene Machtbeziehungen, die im Sinne Foucaults nicht ohne potenzielle Widerstände auskommen.

Die Rolle der Kritik als Form des Widerstandes tritt nach Foucault da auf, wo der widerständige Wille herrscht, „nicht derartig, im Namen dieser Prinzipien da, zu solchen Zwecken und mit solchen Verfahren“ regiert zu werden (Foucault 1992, 11). In dem Vortrag „Was ist Kritik?“29 (1992) ist es in Anlehnung an Immanuel Kant gar ein aufklärerischer Gedanke, der eine kritisch-tugendhafte Haltung gegenüber Regierungsweisen befeuert (vgl. Foucault 1992, 16ff.; vgl. Butler 2009, 227). Kritik, auch verstanden als eine „reflektiert[e] Unfügsamkeit“ gegenüber Regierungsabsichten (Foucault 1992, 15), bedeutet mithin keineswegs, gar nicht regiert werden zu wollen (vgl. Foucault 1992, 11). Vielmehr ist es die Möglichkeit der kritischen Befragung, der Problematisierung selbst, die beständig gegeben sein muss und gar zu einer Haltungsfrage avanciert, um Herrschaftsbeziehungen sowie hegemoniale Regierungseffekte zu vermeiden. Dazu meint Lemke in Rekurs auf

29 Für eine instruktive Auseinandersetzung mit dem Vortrag „Was ist Kritik?“ vgl. Neumeister (2001). 
Foucaults Aufsatz „Was ist Aufklärung“ (1984b): „In diesem Sinne besteht Kritik [nach Foucault, S.K.] weder in der Affirmation des Bestehenden noch seiner Negation, sondern in einer Problematisierung, die sich auf eine tiefere und grundlegendere Ebene richtet, um den gemeinsamen Boden dieser beiden ,Lösungen' zu erforschen“ (Lemke 1997, 355)..30 Damit wird deutlich, dass nicht jede widerständige Haltung kritisch ist, wie Lemke hinzufügt (vgl. Lemke 1997, 355). Im Kontext der Corona-Pandemie kann dahingehend mit Foucault zwischen unkritisch ablehnenden, gar das Coronavirus leugnenden Haltungen und der kritischen Problematisierung von Regierungshandlungen unterschieden werden. Letztere kann durchaus zu einer ablehnenden Haltung gegenüber Regierungsmaßnahmen führen, doch ist sie zunächst und primär kritisch prüfend.

Die Haltung der Kritik ist zwar nicht in dem Sinne normativ zu denken, dass bestimmte Diskurse innerhalb einer „Politik der Wahrheit“ (vgl. Foucault 1992, 15) - worunter Foucault das eigentliche Arbeitsfeld der Philosophie versteht (vgl. Foucault 2004, 15) - vorab disqualifiziert werden. Ausgehend von einer kritischen Haltung kann aber eine Auseinandersetzung mit den sich historisch entwickelnden Wissensformen und Zielrichtungen von Regierungsweisen resultieren. Foucault meint hierzu in einem weiteren Interview: „Kritik heißt nicht, dass man lediglich sagt, die Dinge seien nicht gut so, wie sie sind. Kritik heißt herausfinden [sic], auf welchen Erkenntnissen, Gewohnheiten und erworbenen, aber nicht reflektierten Denkweisen die akzeptierte Praxis beruht" (Foucault 1981, 221). Die Rede ist von einer kritischen Auseinandersetzung, die den öffentlichen Diskurs am Beispiel der Debatten über die Corona-Maßnahmen bereichern würde, anstatt diese mittels Verschwörungstheorien und polemischer Ablehnungshaltungen zum Erliegen zu bringen.

Mit der von Foucault angeregten Haltung der Kritik wird letztlich die Anschauung in Abrede gestellt, (bio)politische Ordnungen seien homogene, unveränderliche Gebilde, die ausschließlich über eigentümliche Strukturmerkmale intelligibel sind. Von dieser Anschauung distanzieren sich Agamben und Esposito meines Erachtens keineswegs. Dennoch soll nicht unerwähnt bleiben, dass sowohl Agamben als auch Esposito jeweils eine Aussicht andeuten, wie die scheinbar notwendigen Ausschlussmecha-

$30 \quad$ Wie es ebenso Andreas Folkers in einem aufschlussreichen Beitrag zu Foucaults Genealogie der Kritik formuliert, geht es der Kritik „nicht nur um die Frage, was wahr und was falsch ist, sondern darum, welche Mechanismen es erlauben, zwischen wahr und falsch zu unterscheiden" (Folkers 2019, 103). 
nismen der biopolitischen Praxis theoretisch subvertiert werden könnten. So lassen sich im Werk Agambens einige Anspielungen auf eine „kommende Politik“ jenseits der Souveränität finden (vgl. Flügel-Martinsen 2011, 38f.; vgl. Agamben 1994, 254), was im Epilog zum letzten Homo-Sacer-Band auch als „Theory of Destituent Potential“ bezeichnet wird (vgl. Agamben 2014). ${ }^{31}$ Esposito hingegen setzt auf eine dekonstruktive Vertiefung des inneren Widerspruches der Immunisierungslogik (vgl. Esposito 2002b, 26). Eine „andere Philosophie der Immunität“ soll dabei das differente Ausgeschlossene biopolitischer Ordnungen als möglichen positiven „Antrieb“ verstehen, der gerade jene biopolitische Ordnung in Frage stellt (Esposito 2002b, 27). Ob Espositos skizzenhafte Neuausrichtung als eine Affirmation der Biopolitik gelten kann, bleibt dabei jedoch eine offene Frage (vgl. Esposito 2008b, 28). ${ }^{32}$

\section{Konklusion: Kritik in Zeiten des Ausnahmezustandes?}

Die fortwährende Corona-Pandemie konfrontiert Gesellschaften weltweit mit Infektionszahlen, Todesraten und unsicheren Prognosen für die Zukunft. Sie verschärft nicht bloß die gravierende soziale und ökonomische Ungleichheit in Europa und anderswo, insoweit insbesondere Risiken ungleich verteilt werden, was wiederum zu einer stärkeren Prekarisierung bestimmter Bevölkerungsschichten führt, sondern liefert auch aktuelle Beispiele biopolitischer Regierungspraktiken: das Schließen nationaler Grenzen, die Verpflichtung zum Tragen von Mund-Nasen-Schutzmasken, die Quarantänemaßnahmen oder die anlaufenden Impfmaßnahmen. Während die Schließung von staatlichen Grenzen einen gesellschaftlichen Ausschluss all jener Menschen bedeutet, die bestimmte Auflagen wie einen Staatsbürgerschaftsnachweis oder andere Aufenthaltsbewilligungen nicht erfüllen, richtet sich die Quarantäne an eine Selektion im Inneren einer Gemeinschaft. Als biopolitisch sind derartige Maßnahmen insofern zu betiteln, als sie sich primär am biologischen, „nackten“ Leben der Menschen einer anvisierten Bevölkerung ausrichten und dieses nach Foucault im Lichte bestimmter Kal-

31 Vgl. hierzu ausführlich den Artikel von Peter Zeillinger (2020), der sich damit auseinandersetzt, wie ein solches „destituent potential“ in der politischen Praxis einer „Gemeinschaft-ohne-Souveränität“ zu denken ist.

32 Näheres zu einer affirmativen Biopolitik findet sich in dem Sammelband von Vittoria Borsò (2014). 
küle steigern, im Sinne Agambens aus der politischen Ordnung zusehends ausgrenzen oder im Verständnis Espositos in besagte Ordnung integrieren, um eine Gemeinschaft längerfristig zu immunisieren und institutionalisierte Lebensformen dauerhaft zu schützen. In der Sprache Foucaults ist es letztlich ein spezieller „Nexus von Macht-Wissen“ (Foucault 1992, 33), später auch eine „Wahrheitsmanifestation“ genannt (vgl. Foucault 2020, 26ff.), die Regierungsmaßnahmen zur Steigerung, aber auch Selektion und Exklusion von Leben eine strategische Zielrichtung verleihen.

Jene doppelte Funktionsweise, die in den Konzepten des Biopolitischen nach Agamben und Esposito ebenfalls repräsentiert ist, lässt jedoch die grundsätzliche Möglichkeit übersehen, als Teil eines Bevölkerungskörpers gegen Regierungsmaßnahmen Widerstand zu leisten. Zwar bleibt zu bemerken, dass sowohl Esposito als auch Agamben ansatzweise einen Versuch unternehmen, die scheinbar unausweichliche Logik biopolitischer Einund Ausschlüsse auf struktureller Ebene zu subvertieren. Was beide Denker nichtsdestoweniger verkennen, sind die eigentümlichen Machtbeziehungen, die sich durch die Praxis des Regierens aufbauen. Diese Machtbeziehungen, die sowohl im Kontext biopolitischer Einschlüsse als auch Ausschlüsse vorherrschen, wie Butler hervorhebt (vgl. Butler 2016, 109), definiert Foucault stets über die Möglichkeit des Widerstandes. Hierdurch wird ein Denken möglich, das biopolitische Regierungstechniken immer schon gegen potenzielle Widerstände arbeiten sieht.

Außerdem wurde gezeigt, dass der Begriff der Gouvernementalität die strukturalen Konzepte der Biopolitik nach Agamben und Esposito um eine „poststrukturale“ Perspektive ergänzt. Denn eine gouvernementale Analyse verläuft abseits festgesetzter Strukturen und in Richtung konkreter Praktiken des Regierens sowie Praktiken des Widerstandes. Tatsächlich bestätigt die rezente Krise zudem, dass Widerstände allgegenwärtig sind, seien es Demonstrierende gegen neue Verordnungen, Unternehmen oder NGOs, die auf sich verschärfende ökonomische oder soziale Missstände hinweisen. Darüber hinaus erlaubt die Analyse biopolitischer Gouvernementalität, den Einfluss zwischenmenschlicher Mikromächte wie auch institutionalisierter Makromächte in den Blick zu nehmen und dadurch zu einer allgemeinen Gesellschaftsanalyse beizutragen.

Welches Fazit können wir zuletzt ziehen, wenn wir gegenwärtig auf die Omnipräsenz der Corona-Pandemie und die zahlreichen Widerstände aus der Bevölkerung blicken? Eine kritische Haltung gegenüber Regierungspraktiken einzunehmen, ist im Sinne Foucaults nicht gleichbedeutend mit 
einer Geste der Ablehnung oder Polemik (vgl. Foucault 1992, 8; vgl. Foucault 2010), wie sie vermehrt Verschwörungsgläubige präsentieren. Angelehnt an Foucault verstehe ich darunter vielmehr eine kritische Prüfung der Formen des Wissens und der strategischen Kalküle, die Regierungstechniken in Bezug auf ein Kollektiv verfolgen. Sind die verfolgten Zwecke wie auch die Mittel zur Zweckverfolgung in Anbetracht der gestellten Problematik angemessen? Mit welchem Wissenskomplex werden biopolitische Ausschlüsse und Einschlüsse getätigt und gerechtfertigt? Handelt es sich bei manch einer Regierungsmaßnahme gegebenenfalls um eine herrschaftliche Praktik, die es nach Foucault grundsätzlich zu vermeiden gilt, da derartige Praktiken über Repressionsmechanismen agieren? Die Kritik soll mit Butler gesprochen „das System der Bewertung selbst herausarbeiten“ (Butler 2009, 225), um sodann in einem zweiten Schritt über die zugrundeliegenden Wissenskomplexe, Begründungsmuster und gesellschaftlichen Wertideale debattieren zu können. Schlussendlich ist es Foucaults Konzept der biopolitischen Gouvernementalität, mit dem dieser normative Anspruch der Kritik in Zeiten des Coronavirus in den Blick zu bekommen ist.

\section{Literatur}

Agamben, Giorgio. 1994. „Lebens-Form“. In Gemeinschaften. Positionen zu einer Philosophie des Politischen, herausgegeben von Joseph Vogl, 1. Aufl., 251-257. Frankfurt/Main: Suhrkamp.

Agamben, Giorgio. 2002. Homo sacer. Die souveräne Macht und das nackte Leben. 1. Aufl. Frankfurt am Main: Suhrkamp.

Agamben, Giorgio. 2004. Ausnahmezustand. 1. Aufl. Frankfurt/Main: Suhrkamp.

Agamben, Giorgio. 2009. Signatura rerum. Zur Methode. 1. Aufl. Frankfurt/Main: Suhrkamp.

Agamben, Giorgio. 2014. The Use of Bodies. Homo Sacer IV,2. 1. Aufl. Stanford: Stanford UP.

Agamben, Giorgio. 2020. „The state of exception provoked by an unmotivated emergency“. positionspolitics, Februar 26, 2020. http://positionswebsite.org/giorgio-agamben-the-state-of-exception-provoked-by-an-unmotivated-emergency/.

Bedorf, Thomas. 2013. „Sozial, politisch, biopolitisch. Die soziale Marktwirtschaft und die Krise“. In Die Kunst, das Leben zu „bewirtschaften“. Biós zwischen Politik, Ökonomie und Ästhetik, herausgegeben von Vittoria Borsò und Michele Cometa, 1. Aufl., 69-82. Bielefeld: transcript. https://doi.org/10.14361/transcript. 9783839417560 . 
Bohlender, Matthias. 2006. „Michel Foucault - Für eine Geschichte und Kritik der politischen Vernunft“. In Politische Ideengeschichte im 20. Jahrhundert. Konzepte und Kritik, herausgegeben von Harald Bluhm und Jürgen Gebhardt, 1. Aufl., 89-106. Baden-Baden: Nomos.

Borsò, Vittoria, Hrsg. 2014. Wissen und Leben - Wissen für das Leben. Herausforderungen einer affirmativen Biopolitik. 1. Aufl. Bielefeld: transcript. https://doi. org/10.14361/transcript.9783839421604.

Braun, Kathrin, und Helene Gerhards, Hrsg. 2019. Biopolitiken - Regierungen des Lebens heute, 1. Aufl. Wiesbaden: Springer VS. https://doi.org/10.1007/978-3658-25769-9.

Bröckling, Ulrich. 2010. „Nachwort“. In Kritik des Regierens. Schriften zur Politik. Auswahl und Nachwort von Ulrich Bröckling, 1. Aufl., 401-439. Berlin: Suhrkamp.

Buchstein, Hubertus, und Katharina Beier. 2011. „Biopolitik“. In Politische Theorie. 25 umkämpfte Begriffe zur Einführung, herausgegeben von Gerhard Göhler, Mattias Isler und Ina Kerner, 2. Aufl., 29-45. Wiesbaden: Springer VS.

Butler, Judith. 2009. „Was ist Kritik? Ein Essay über Foucaults Tugend“. In Was ist Kritik?, herausgegeben von Rahel Jaeggi und Tilo Wesche, 1. Aufl., 221-246. Frankfurt/Main: Suhrkamp.

Butler, Judith. 2016. Anmerkungen zu einer performativen Theorie der Versammlung. 1. Aufl., Berlin: Suhrkamp.

Campbell, Timothy, und Adam Sitze, Hrsg. 2013. Biopolitics: A Reader. 1. Aufl., Durham: Duke UP.

Demirovic, Alex. 2008. „Liberale Freiheit und das Sicherheitsdispositiv. Der Beitrag von Michel Foucault“. In Gouvernementalität und Sicherheit. Zeitdiagnostische Beiträge im Anschluss an Foucault, herausgegeben von Patricia Purtschert, Katrin Meyer und Yves Winter, 1. Aufl., 229-250. Bielefeld: transcript. https://doi. org/10.14361/9783839406311.

Esposito, Roberto. 2004a. Communitas. Ursprung und Wege der Gemeinschaft. 1. Aufl., Berlin: diaphanes.

Esposito, Roberto. 2004b. Immunitas. Schutz und Negation des Lebens. 1. Aufl., Berlin: diaphanes.

Esposito, Roberto. 2008a. Bios. Biopolitics and Philosophy. 1. Aufl., Minneapolis: University of Minnesota Press.

Esposito, Roberto. 2008b. Person und menschliches Leben. Berlin: diaphanes.

Esposito, Roberto. 2010. „Vom Unpolitischen zur Biopolitik“. In Das Politische und die Politik, herausgegeben von Thomas Bedorf und Kurt Röttgers, 1. Aufl., 89101. Berlin: Suhrkamp.

Esposito, Roberto. 2014. „Das Paradigma der Immunisierung“. In Biopolitik. Ein Reader, herausgegeben von Andreas Folkers und Thomas Lemke, 1. Aufl., 337382. Berlin: Suhrkamp. 
Esposito, Roberto. 2020. „Biopolitik wird nie aktueller sein als heute“. Neue Züricher Zeitung, Mai 16, 2020. https://www.nzz.ch/feuilleton/coronavirus-roberto-esposito-ueber-moderne-biopolitik-ld.1556128.

Flügel-Martinsen, Oliver. 2011. „Giorgio Agambens Erkundungen der politischen Macht und das Denken der Souveränität“. In Der Nomos der Moderne. Die politische Philosophie Giorgio Agambens, herausgegeben von Daniel Loick, 1. Aufl., 23-40. Baden-Baden: Nomos. https://doi.org/10.5771/9783845232430.

Folkers, Andreas. 2019. „Veridiktion und Denunziation. Foucaults Genealogie der Kritik und die Politik der Wahrheit“. In Foucault und das Politische. Transdisziplinäre Impulse für die politische Theorie der Gegenwart, herausgegeben von Oliver Marchart und Renate Martinsen, 1. Aufl., 87-107. Wiesbaden: Springer VS. https://doi.org/10.1007/978-3-658-22789-0.

Folkers, Andreas. 2020. „Vorwegnahme, Herausnahme und Hereinnahme“. Soziopolis, April 4, 2020. https://soziopolis.de/beobachten/gesellschaft/artikel/vorwegnahme-herausnahme-und-hereinnahme/.

Foucault, Michel. 1976. Der Wille zum Wissen. Sexualität und Wahrheit I, 21. Auflage. Frankfurt/Main: Suhrkamp.

Foucault, Michel. 1979. „Omnes et singulatim‘: zu einer Kritik der politischen Vernunft“. In Analytik der Macht. Auswahl und Nachwort von Thomas Lemke, 1. Aufl., 188-219. Frankfurt/Main: Suhrkamp 2005 [DE IV, 165-197].

Foucault, Michel. 1980. „Gespräch mit Ducio Trombadori“. In Schriften in vier Bänden. Dits et Écrits. Band IV, herausgegeben von Daniel Defert und Jaques Lagrange, 1. Aufl., 51-118. Frankfurt/Main: Suhrkamp 2005.

Foucault, Michel. 1981. „Ist es also wichtig, zu denken?“. In Schriften in vier Bänden. Dits et Écrits. Band IV, herausgegeben von Daniel Defert und Jaques Lagrange, 1. Aufl., 219-223. Frankfurt/Main: Suhrkamp 2005.

Foucault, Michel. 1982. „Subjekt und Macht“. In Analytik der Macht. Auswahl und Nachwort von Thomas Lemke, 1. Aufl., 240-263. Frankfurt/Main: Suhrkamp 2005 [DE IV, 269-294].

Foucault, Michel. 1984a. „Die Ethik der Sorge um sich als Praxis der Freiheit“. In Analytik der Macht. Auswahl und Nachwort von Thomas Lemke, 1. Aufl., 274301. Frankfurt/Main: Suhrkamp 2005 [DE IV, 875-902].

Foucault, Michel. 1984b. „Was ist Aufklärung?“. In Schriften in vier Bänden. Dits et Écrits. Band IV, herausgegeben von Daniel Defert und Jaques Lagrange, 1. Aufl., 687-707. Frankfurt/Main: Suhrkamp 2005.

Foucault, Michel. 1992. Was ist Kritik? 1. Aufl. Berlin: Merve Verlag.

Foucault, Michel. 1994. Überwachen und Strafen. Die Geburt des Gefängnisses. 1. Aufl. Frankfurt/Main: Suhrkamp.

Foucault, Michel. 1996. In Verteidigung der Gesellschaft. Vorlesungen am Collège de France 1975/76. 5. Aufl. Frankfurt/Main: Suhrkamp.

Foucault, Michel. 2001. Die Ordnung des Diskurses. Frankfurt/Main: Fischer. 
Foucault, Michel. 2004. Sicherheit, Territorium, Bevölkerung. Geschichte der Gouvernementalität I. Vorlesungen am Collège de France 1978/79. 5. Aufl. Frankfurt/Main: Suhrkamp.

Foucault, Michel. 2006. Die Geburt der Biopolitik. Geschichte der Gouvernementalität II. Vorlesungen am Collège de France 1978/79. 6. Aufl. Frankfurt/Main: Suhrkamp.

Foucault, Michel. 2010. „Polemik, Politik, Problematisierung“. In Kritik des Regierens. Auswahl und Nachwort von Ulrich Bröckling. 1. Aufl. 258-267. Berlin: Suhrkamp [DE IV, 724-733].

Foucault, Michel. 2020. Die Regierung der Lebenden. Vorlesung am Collège de France 1979/80. 1. Aufl. Frankfurt/Main: Suhrkamp.

Gehring, Petra. 2006. Was ist Biomacht? Vom zweifelhaften Mehrwert des Lebens. 1. Aufl. Frankfurt/Main: Campus.

Geyer, Christian, Hrsg. 2001. Biopolitik. Die Positionen. 1. Aufl. Frankfurt/Main: Suhrkamp.

Gorgoglione, Ruggiero. 2016. Paradoxien der Biopolitik. Politische Philosophie und Gesellschaftstheorie in Italien. 1. Aufl. Bielefeld: transcript. https://doi. org/10.14361/9783839434000.

Graumann, Sigrid, und Ingrid Schneider, Hrsg. 2003. Verkörperte Technik - Entkörperte Frau. Biopolitik und Geschlecht. 1. Aufl. Frankfurt, New York: Campus.

Hardt, Michael, und Antonio Negri. 2002. Empire. Die neue Weltordnung. 1. Aufl. Frankfurt, New York: Campus.

Laufenberg, Mike. 2016. „Kritik der biopolitischen Souveränität. Butler und Foucault“. In Staat, Politik, Ethik. Zum Staatsverständnis Judith Butlers, herausgegeben von Lars Distelhorst, 1. Aufl., 17-39. Berlin: Nomos. https://doi. org/10.5771/9783845254760.

Lemke, Thomas. 1997. Eine Kritik der politischen Vernunft. Foucaults Analyse der modernen Gouvernementalität, 1. Aufl., Berlin, Hamburg: Argument.

Lemke, Thomas. 2000. „Neoliberalismus, Staat und Selbsttechnologien. Ein kritischer Überblick über die governmentality studies“. In Politische Vierteljahresschrift 41(1), 31-47. Wiesbaden: Westdeutscher Verlag. https://doi.org/10.1007/ s11615-000-0003-8.

Lemke, Thomas. 2001. „Gouvernementalität“. In Michel Foucault. Eine Einführung in sein Denken, herausgegeben von Marcus S. Kleiner, 1. Aufl., 108-122. Frankfurt/Main: Campus.

Lemke, Thomas. 2003. „Rechtssubjekte oder Biomasse? Reflexionen zum Verhältnis von Rassismus und Exklusion“. In Biopolitik und Rassismus, herausgegeben von Martin Stingelin, 1. Aufl., 160-183. Frankfurt/Main: Suhrkamp.

Lemke, Thomas. 2004. „Die Regel der Ausnahme“. Deutsche Zeitschrift für Philosophie. 52(6): 943-963. https://doi.org/10.1524/dzph.2004.52.6.943. 
Lemke, Thomas. 2008. „Eine Analytik der Biopolitik. Überlegungen zu Geschichte und Gegenwart eines umstrittenen Begriffs“. Behemoth 1: 72-89. https://doi. org/10.6094/behemoth.2008.1.1.755.

Lemke, Thomas. 2016. „Die politische Theorie der Gouvernementalität“. In Politische Theorien der Gegenwart I. Eine Einführung, herausgegeben von André Brodocz und Gary S. Schaal, 4. Aufl., 480-510. Opladen und Toronto: Barbara Budrich.

Lemke, Thomas, Susanne Krasmann und Ulrich Bröckling. 2000. „Gouvernementalität, Neoliberalismus und Selbsttechnologien. Eine Einführung“. In Gouvernementalität der Gegenwart. Studien zur Ökonomisierung des Sozialen, herausgegeben von Thomas Lemke, Susanne Krasmann und Ulrich Bröckling, 1. Aufl., 7-40. Frankfurt/Main: Suhrkamp.

Lorey, Isabell. 2011. Figuren des Immunen. Elemente einer politischen Theorie. 1. Aufl. Zürich: diaphanes.

Meyer, Katrin, und Patricia Purtschert. 2008. „Migrationsmanagement und die Sicherheit der Bevölkerung". In Gouvernementalität und Sicherheit. Zeitdiagnostische Beiträge im Anschluss an Foucault, herausgegeben von Patricia Purtschert, Katrin Meyer und Yves Winter, 1. Aufl., 149-173. Bielefeld: transcript. https:// doi.org/10.14361/9783839406311.

Muhle, Maria. 2007. „Bio-Politik versus Lagerparadigma. Eine Diskussion anhand des Lebensbegriffs bei Agamben und Foucault“. In Auszug aus dem Lager. Zur Überwindung des modernen Raumparadigmas, herausgegeben von Ludger Schwarte, 1. Aufl., 78-95. Bielefeld: transcript. https://doi.org/10.14361/9783839405505.

Muhle, Maria. 2008. Eine Genealogie der Biopolitik. Zum Begriff des Lebens bei Foucault und Canguilhem. 1. Aufl. Bielefeld: transcript.

Muhle, Maria, und Kathrin Thiele, Hrsg. 2011. Biopolitische Konstellationen. 1. Aufl. Berlin: August.

Neumeister, Bernd. 2001. Kritik und Aufklärung. In Michel Foucault. Eine Einführung in sein Denken, herausgegeben von Marcus S. Kleiner, 1. Aufl., 191-202. Frankfurt/Main: Campus.

Pieper, Marianne, Thomas Atzert, Serhat Karakayalı und Vassilis Tsianos, Hrsg. 2007. Empire und die biopolitische Wende. Die internationale Diskussion im Anschluss an Hardt und Negri. 1. Aufl. Frankfurt, New York: Campus.

Pieper, Marianne, Thomas Atzert, Serhat Karakayalı und Vassilis Tsianos, Hrsg. 2011. Biopolitik - in der Debatte. 1. Aufl. Wiesbaden: Springer VS. https://doi. org/10.1007/978-3-531-92807-4.

Preciado, Paul. 2020. „Vom Virus lernen“. Hebbel am Ufer, April 7, 2020. https:// www.hebbel-am-ufer.de/hau300o/vom-virus-lernen.

Reese-Schäffer, Walter. 2009. „Man erkennt sehr leicht den Einfluss Husserls ... Wie weit trägt die Interpretation des Ordoliberalismus durch Michel Foucault?“. In Phänomenologie und die Ordnung der Wirtschaft, herausgegeben von Hans-Helmuth Gander, Nils Goldschmidt und Uwe Dathe, 1. Aufl., 103-125. Würzburg: Ergon. 
Reuschling, Felicita. 2006. „Homo Sacer und die Linke Biopolitik“. In ,Das Leben lebt nicht', herausgegeben von die röteln, 1. Aufl., 59-73. Berlin: Verbrecher Verlag.

Rose, Nikolas. 2014. „Die Politik des Lebens selbst“. In Biopolitik. Ein Reader, herausgegeben von Andreas Folkers und Thomas Lemke, 1. Aufl., 420-467. Berlin: Suhrkamp.

Ruoff, Michael. 2018. Foucault-Lexikon. Entwicklung - Kernbegriffe - Zusammenhänge. 4. Auflage. Paderborn: Fink.

Saar, Martin. 2009. „Macht und Kritik“. In Sozialphilosophie und Kritik, herausgegeben von Rainer Forst, Martin Hartmann, Rahel Jaeggi und Martin Saar, 1. Aufl., 567-587. Frankfurt/Main: Suhrkamp.

Sarasin, Philipp. 2003. „Zweierlei Rassismus? Die Selektion des Fremden als Problem in Michel Foucaults Verbindung von Biopolitik und Rassismus“. In Biopolitik und Rassismus, herausgegeben von Martin Stingelin, 1. Aufl., 55-79. Frankfurt/ Main: Suhrkamp.

Sarasin, Philipp. 2005. „Ausdünstungen, Viren, Resistenzen. Die Spur der Infektion im Werk Michel Foucaults“. In Österreichische Zeitschrift für Geschichtswissenschaften 16(3): 88-108. https://doi.org/10.25365/oezg-2005-16-3-6.

Sarasin, Philipp. 2019. „Foucaults Wende“. In Foucault und das Politische. Transdisziplinäre Impulse für die politische Theorie der Gegenwart, herausgegeben von Oliver Marchart und Renate Martinsen, 1. Aufl., 9-22, Wiesbaden: Springer VS. https://doi.org/10.1007/978-3-658-22789-0.

Sarasin, Philipp. 2020. „Mit Foucault die Pandemie verstehen?“. Geschichte der Gegenwart, März 25, 2020. https://geschichtedergegenwart.ch/mit-foucault-die-pandemie-verstehen.

Scheu, Johannes. 2014. „Der blinde Fleck: Biopolitik, Staatsrassismus und Gouvernementalität bei Michel Foucault und Giorgio Agamben“. In Gouvernementalität, Staat und Weltgesellschaft. Studien zum Regieren im Anschluss an Foucault, herausgegeben von Andreas Vasilache, 1. Aufl., 59-82. Wiesbaden: Springer VS. https://doi.org/10.1007/978-3-658-02577-9.

Spieker, Manfred, Hrsg. 2009. Biopolitik. Probleme des Lebensschutzes in der Demokratie. 1. Aufl. Paderborn: Ferdinand Schöningh.

Unterthurner, Gerhard. 2016. „Eine Genealogie europäischer Rationalitätsformen Anmerkungen zur Biomacht nach Foucault“. In Bruchlinien Europas. Philosophische Erkundungen bei Badiou, Adorno, Zizek und anderen, herausgegeben von Gerhard Unterthurner und Erik M. Vogt, 1. Aufl., 157-188. Wien: Turia + Kant.

Van den Daele, Wolfgang. 2005. Biopolitik. Sonderheft 23. Wiesbaden: Verlag für Sozialwissenschaften.

Zeillinger, Peter. 2020. „Das Unvereinbare im Zentrum des Politischen.Zum politischen Potenzial von Agambens Homo-Sacer-Projekt“. In Subversiver Messianismus. Interdisziplinäre Agamben-Lektüren, herausgegeben von Martin Kirschner, 1. Aufl., 245-304. Baden-Baden: Academia. https://doi.org/10.5771/9783896658623. 
